\title{
A construção do vínculo no atendimento psicológico on-line de agentes de segurança pública e seus familiares no contexto pandêmico
}

\author{
Michelle Oliveira da Silva ${ }^{1}$ \\ Taynã Aparecido Botelho ${ }^{2}$ \\ Vinícius Correia Cavalcanti Dantas ${ }^{3}$ \\ Renan Vieira de Santana Rocha ${ }^{4}$ \\ Beatriz Borges Brambilla ${ }^{5}$
}

\section{RESUMO}

Este estudo busca relatar a experiência de formandos em psicologia no atendimento on-line de agentes de segurança pública e seus familiares, a partir de uma experiência de estágio supervisionado na cidade de Salvador/BA. Diante do contexto pandêmico, os formandos de uma determinada instituição tiveram a sua experiência de estágio, previamente planejada como presencial, adaptada para o modelo remoto, sendo tais atendimentos realizados, por meio de uma plataforma virtual e na perspectiva da saúde do trabalhador, ao longo do ano de 2020. O presente artigo, assim, tem por método de pesquisa o Relato de Experiência, e procura abordar as vivências pessoais dos estagiários frente aos desafios vinculares e outras particularidades implicadas diante do sofrimento dentro e fora do trabalho, bem como do conhecimento teórico-técnico sobre a temática em tela.

Palavras-chave: Psicologia. Segurança Pública. Atendimento Online. Pandemia. Vínculo Terapêutico.

\footnotetext{
${ }^{1}$ michelle_olivy12@hotmail.com - Centro Universitário Ruy Barbosa (UniRuy/Wyden)

2 psi.taynabotelho@gmail.com - Centro Universitário Ruy Barbosa (UniRuy/Wyden)

${ }^{3}$ vccdantas@gmail.com - Centro Universitário Ruy Barbosa (UniRuy/Wyden)

${ }^{4}$ renanvsr@gmail.com - Centro Universitário Ruy Barbosa (UniRuy/Wyden)

${ }^{5}$ comafetividade@gmail.com - Pontifícia Universidade Católica de São Paulo (PUC-SP)
} 


\section{The construction of the bond in the online psychological service of public security agents and their families in the pandemic context}

\section{ABSTRACT}

This study seeks to report the experience of trainees in psychology in online care for public security agents and their families, from a supervised internship experience, in the city of Salvador/BA. In view of the pandemic context, the trainees of a certain basic school had their internship experience, previously planned as in-person, adapted to the remote model, such services being performed, through a virtual platform and from the perspective of the worker's health, over the year 2020. The present article, therefore, uses the Experience Report as a research method, and seeks to address the trainees' personal experiences in the face of specific challenges and other particularities involved, in the face of suffering inside and outside work, as well as knowledge theoretical-technical on the topic at hand.

Keywords: Psychology. Public Security. Online Service. Pandemic. Therapeutic Bond. 
No início do ano de 2020, vimo-nos inseridos em um contexto absolutamente novo. Em um curto espaço de tempo, assistimos um vírus desconhecido avançar países, continentes até atingir uma escala mundial, transmutando-se de uma epidemia para uma pandemia, carregando consigo consequências inimagináveis, até então. No Brasil, o primeiro caso de que se tem registro data de 26 de fevereiro de 2020; logo, uma realidade que parecia ser distante, tornou-se assunto principal dos meios de comunicação, revelando, inclusive, possíveis agravos à saúde mental em diferentes esferas da vida cotidiana (ROCHA; BRAMBILLA; BARROS, 2020).

A partir disso, importantes medidas de saúde foram estabelecidas e interferiram completamente no comportamento de todas as pessoas. Para além de lavar as mãos e fazer o uso regular de álcool em gel, o distanciamento social mostrou-se a medida de combate mais eficaz à disseminação do novo coronavírus. Sendo assim, novos arranjos precisaram ser estabelecidos em todas as profissões, destacando-se o estabelecimento do trabalho em casa a fim de garantir a continuidade de atividades laborais e educacionais, sem desrespeitar as indicações da Organização Mundial da Saúde (OMS), de acordo com Teixeira et al. (2020). Dentro da psicologia não foi diferente, já que em um período no qual os possíveis agravos à saúde mental se potencializam, a oferta de cuidados tornou-se fundamental na qualificação da assistência em saúde oferecida à população (ROCHA; BRAMBILLA; BARROS, 2020).

A prática clínico-pedagógica em psicologia, por sua vez, que normalmente era realizada pelos estudantes estagiários dos cursos de psicologia de maneira presencial, também precisou passar por adaptações a partir da publicação da portaria n 544/2020 do Ministério da Educação (MEC), que entrou em vigor em junho de 2020, autorizando a realização de práticas de estágio remotas, ao dispor sobre a "substituição de aulas presenciais por aulas em meios digitais" (BRASIL, 2020b). A partir disso, foi possível e necessário realizar uma nova instrumentalização dos estudantes, tanto prática quanto teórica, para enfrentar esses contextos e territórios novos ante a psicologia. Apesar da prática do atendimento on-line já ter sido regulamentada para profissionais há alguns anos - tendo em vista as resoluções CFP n 11/2012 e 11/2018 -, a obrigatoriedade do contexto remoto, imposta pela vivência pandêmica, trouxe uma nova roupagem para essa oferta de serviços - representada pela resolução CFP n 04/2020 (CFP, 2012; 2018; 2020b).

Sem considerar exclusivamente a pandemia, contudo, vale ponderar que o desenvolvimento tecnológico possibilitou que as distâncias se encurtassem, as barreiras geográficas não mais correspondessem a empecilhos de comunicação e as relações sociais transpusessem línguas e culturas, intercaland o-se entre o físico e o virtual. Os meios tecnológicos "invadiram", inclusive, as instâncias da saúde, e otimizaram as redes de assistência e a acessibilidade à prestação de serviços; inclusive na psicologia, com a psicoterapia on-line.

Assim, cabe uma breve conceituação e diferenciação de dois aspectos que se conectam, mas que também se distinguem, quando pensamos nessas práticas em psicologia: as intervenções baseadas na internet e a psicoterapia on-line. 
A primeira corresponde a uma relação assíncrona; ou seja, as duas pessoas envolvidas não estão conectadas ao mesmo tempo, sendo que essas intervenções são "constituídas por programas computadorizados, nos quais pode ou não haver a participação do terapeuta, que incluem a utilização de softwares, CDs, DVDs, realidade virtual, aplicativos de smartphones, tarefas e feedback on-line" (ASSI; THIEME, 2020, p. 270), que tem por objetivo contribuir para a prevenção ou melhora de quadros de transtornos mentais, por exemplo (PINTO, 2002; PIETA; GOMES, 2014; PIETA et al., 2015; SIEGMUND; NONOHAY; GAUER, 2016), podendo conter informações a respeito do diagnóstico ou outros aspectos que abraçam a condição do sujeito que faz uso. Cabe salientar que tal mecanismo tem por restrição o envolvimento de pessoas com quadros psicóticos e com "alto grau de ansiedade e angústia” (ASSI; THIEME, 2020, p. 270). Já a psicoterapia on-line tem por configuração o encontro de ambos os envolvidos, ao mesmo tempo, em meio virtual, seja por "mensagem instantânea, chat, áudio ou videoconferência, sem excluir a possibilidade de se realizar encontros presenciais" (ASSI; THIEME, 2020, p. 270).

Segundo Siegmund e Lisboa (2015), a relação da psicologia com a internet teve seu início no ano de 1995, a partir da construção de um site pelo Núcleo de Pesquisa da Psicologia em Informática (NPPI), da Pontifícia Universidade Católica de São Paulo (PUC-SP), atualmente conhecido como JANUS (Laboratório de Estudos de Psicologia e Tecnologia da Informação e Comunicação), com o intuito de estudar e conhecer o novo fenômeno mundial: a internet. Esse projeto, contrariamente, fomentou a procura do serviço de atendimento virtual, o que até então não era viável e nem o objetivo do site, fazendo com que a instituição veiculasse informações educativas e encaminhamentos desses sujeitos que procuravam o atendimento virtual para atendimentos presenciais. A demanda continuou crescendo, o que fez com que o NPPI buscasse o auxílio do Conselho Federal de Psicologia (CFP), que o orientou à manutenção das respostas indicando a impossibilidade de realização de psicoterapia virtual - inclusive sob o amparo da resolução CFP n 02/1995, normativa que vedava a realização da chamada "TelePsicologia". Desse ponto em diante, o CFP, junto aos Conselhos Regionais de Psicologia (CRPs) travaram - e seguem travando - discussões acerca do atendimento psicológico on-line, em seus limites e possibilidades (CFP, 1995).

Desde então, algumas resoluções foram elaboradas, revogadas e reelaboradas. A primeira a ser publicada, em substituição a de $n^{\circ}$ 02/1995, foi a $n^{\circ} 03 / 2000$, que tinha por objetivo regulamentar o uso de computadores em psicologia, a partir da Resolução do Conselho Nacional de Saúde (CNS) de n 196/1996, que autorizava a realização de pesquisas na área de informática para as mais diversas profissões da saúde (CFP, 2000; BRASIL, 1996). Posteriormente, foi publicada a resolução CFP $n^{\circ} 12 / 2005$, que estabelecia diretrizes e orientações sobre como proceder com alguns modelos de atendimentos já autorizados, indicando a quantidade de sessões e a autorização do uso de softwares como veículos de informação educativa. Além disso, essa resolução estabelecia também a obrigatoriedade do cadastro do site utilizado junto aos CRPs, como estratégia de monitoramento destes avanços (CFP, 2005).

Apesar disso, no ano de 2012, com a revogação da resolução anterior e a elaboração da resolução CFP $n^{\circ}$ 11/2012, foi-se ampliado o leque de possíveis intervenções psicológicas em ambiente virtual, permitido o aumento do número de sessões e os atendimentos on-line em 
situações específicas: quando o paciente do atendimento presencial estivesse em trânsito ou quando se encontrasse impossibilitado de comparecer ao atendimento tradicional.

No ano de 2018, outrossim, surge a resolução CFP $n^{\circ} 11 / 2018$, que revoga todas as resoluções anteriores e estabelece novas e mais enfáticas diretrizes, não havendo mais limites de sessões, mas instituindo uma obrigatoriedade de cadastro dos psicólogos atuantes em psicoterapia on-line na plataforma do e-Psi, gerida pelo Conselho Federal e pelos Conselhos Regionais de Psicologia, reunindo assim todos os profissionais em uma mesma plataforma digital e sob o amparo de uma resolução única e também comum (CFP, 2018). Essa é a resolução que se encontra em vigor até os dias atuais, apenas atualizada pela resolução CFP n 04/2020, que trouxe algumas adequações técnicas mais específicas ao contexto de pandemia ora vivenciado (CFP, 2020b).

De acordo Faria (2019) e Rodrigues (2014), a psicoterapia on-line tem suas vantagens e limitações. Com relação aos sujeitos que buscam atendimento, essa modalidade favorece as pessoas que possuem: restrições de mobilidade; condições psicológicas como o pânico, que as paralisam diante da mobilidade, mesmo que em viagens curtas; mulheres gestantes ou que não tem com quem deixar os filhos para ir até o local da psicoterapia; indivíduos com agenda de trabalho restrita ou que estejam em constantes viagens; além de pessoas que tenham dificuldades em se expressar diante da presença física da outra pessoa.

Já os limites que se colocam à psicoterapia on-line são caracterizados como: a precariedade de acesso à internet; a escolaridade, no que tange ao conhecimento de informática (ORMAN E O'DEA, 2018 apud FARIA, 2019); desvio do contato visual; "risco da quebra de sigilo [...] e elitismo, embora ressalte que essa última característica ocorra também na modalidade presencial” (FINFGELD, 1999 apud RODRIGUES, 2014, p. 24).

E, ainda com relação à segurança dos dados, Barnet (2003 apud RODRIGUES 2014) aponta ainda ações que podem colaborar, como:

[...] uso de senha ou criptografia de todas as informações confidenciais do paciente; acesso limitado ao computador; backup de todos os dados do computador em discos, com a certeza de que estes sejam guardados em local secreto; ao descartar discos usados, usar programa que apague arquivos, imprimindo caracteres aleatórios sobre eles para que os dados apagados não possam ser reconstituídos; e uso de firewall para ajudar a prevenir o acesso não autorizado a materiais confidenciais através da internet (BARNET, 2003 apud RODRIGUES, 2014, p. 28).

Considerando todas essas tecnologias e as novidades que impõem frente ao meio psicoterápico, a construção do vínculo terapêutico frente ao ambiente on-line se destaca, para os psicólogos, como algo de relevante significação. Algumas pesquisas, como a de Cook e Doyle (2002 apud FARIA, 2019), apresentaram dados que indicaram certa qualidade nessa vinculação. No estudo citado, por exemplo, foram identificadas altas taxas, em meio on-line, de vinculação e comprometimento com a terapia, assim como no estudo de Pietra (2014 apud FARIA, 2019, p. 70), que apresentou evidências de "presença, confiança, conexão, compreensão e participação do paciente" na relação terapêutica. Assim, fica patente que o meio virtual não é um fator que compromete o estabelecimento do vínculo terapêutico, já que tal ferramenta demanda, por parte 
do terapeuta, de uma construção empática, e não da simples necessidade de estarem ambos no mesmo espaço geográfico (COOK; DOYLE, 2002 apud FARIA, 2019; SIEGMUND et al., 2015; SIEGMUND; LISBOA, 2015; SIEGMUND; NONOHAY; GAUER, 2016).

De posse de todas essas informações preliminares, apresentamos o presente estudo. Este tem por objetivo relatar a experiência de formandos em psicologia no atendimento on-line de agentes de segurança pública e seus familiares no contexto da pandemia da COVID-19. Como caminho metodológico percorrido, o início do estágio supervisionado, no serviço-escola de psicologia, deu-se com a realização de capacitações básicas para o manejo de recursos tecnológicos on-line no âmbito da atuação em psicologia. Em seguida, foram iniciadas as supervisões, também de forma virtual e sincrônica, sendo sempre pautadas discussões teóricastécnicas alicerçadas na saúde do trabalhador, conforme a saúde coletiva. Durante os encontros, logo, foram utilizadas ferramentas, como a apresentação crítica de textos relacionados às intervenções; revisões bibliográficas; e artigos sobre a interface entre a segurança pública e a saúde mental, por cerca de um mês.

Assim, quando ao método, no período de três meses, foram atendidas seis pessoas, com a periodicidade de um ou dois encontros semanais, de acordo com a demanda apresentada pelos pacientes. A partir dos atendimentos e das supervisões às sextas-feiras, das $14 \mathrm{~h}$ às $17 \mathrm{~h}$, os discentes centralizaram o ponto da construção vincular como a chave desafiadora para o desenrolar da psicoterapia e como temática mobilizadora para construção do presente estudo, que metodologicamente se fundamenta como um Relato de Experiência (RE). Sobre tal método, Daltro e Faria (2019, p. 235) consideram como "uma importante narrativa científica afinada à condição pós-moderna". Ainda na fala de ambas as autoras, o RE tem por finalidade alinhar o caráter experimental pessoal com os ditames das teorias, permitindo um material rico e legitimado no meio científico.

Para além disso, o relato traz um caráter descritivo, tendo por missão abordar aspectos quanto ao público atendido, recursos utilizados, período em que ocorreu e os procedimentos que envolveram experiência. Torna-se importante, dentro desse contexto, trazer a interface entre a expectativa e o vivido como recurso para pautar no que resultou a experiência, o que foi abstraído enquanto aprendizagem, além de ser relevante uma abordagem quanto às descobertas, dificuldades e recomendações dentro do tema abordado. Logo, esse modelo de produção, como método, tende a contribuir de forma significativa para sua área de atuação já que se apresenta como uma oportunidade de estimular a discussão e troca de proposição de ideias para a melhoria no cuidado com a saúde (DALTRO; FARIA, 2019).

Sobre a saúde do trabalhador e, em especial, a dos profissionais da segurança pública, algumas pesquisas e estudos com foco sanitário voltado aos trabalhadores foram bastante difundidos no Brasil, como apontam Souza e Minayo (2005), especialmente, na área industrial, durante o século XX. Ainda assim, carecem estudos que abordem, em específico, a saúde dos servidores da segurança pública. Em geral, ao se falar em saúde, principalmente, entre agentes de segurança pública, leva-se em conta a saúde física, e não a saúde mental desses profissionais (OLIVEIRA; SANTOS, 2010). Minayo, Assis e Oliveira (2011) afirmam que ainda necessitam-se pesquisas científicas que dialoguem e embasem temas como trabalhos voltados para a saúde, 
intervenções psicossociais, e que levem em consideração as condições físicas e mentais de profissionais de segurança pública no Brasil e na América Latina.

Por tudo isso, o sofrimento dos agentes de segurança pública se mostra multifacetado e imbricado em vários fatores, elencando-se prioritariamente o psicológico, o social e o laboral. Dessa forma, o olhar para esse fenômeno precisa ser a partir da complexidade que tal exige, em conjunto com os familiares que fazem parte da rede social de apoio desses profissionais - o que, em psicologia, intentaremos, a partir deste relato de experiência (DALTRO; FARIA, 2019), aqui, defender.

\section{RELATO DE UMA EXPERIÊNCIA DE ESTÁGIO NA PANDEMIA}

A prática na psicologia é essencial e obrigatória para o aprendizado dos discentes em seu último ano de graduação. O presente relato busca trazer as vivências e experiências dos formandos decorrentes do atendimento on-line. É importante salientar que tal estágio curricular se deu no período de julho a dezembro do ano de 2020, com carga horária de 12 horas semanais.

\subsection{Em tela, uma Conexão Desconhecida}

Os encontros humanos vislumbram aspectos de grandes transformações sociais. São nas relações que os sujeitos se veem, constroem-se e se refazem, o que ocasiona na formação identitária a que se chama de "Eu". Tendo em vista a importância dos encontros, encara-se o espaço terapêutico como um dos locais de maior importância para a transformação, em que se torna possível o defronte consigo e com todos os aspectos que circundam o psiquismo do ser humano. Esse acontecimento evidencia-se no fenômeno do vínculo terapêutico que se estabelece e possibilita o relaxamento das paredes da resistência que os sujeitos constroem em sua subjetividade, a fim de protegerem suas vulnerabilidades. Barbosa e Bosi (2017) afirmam que no vínculo impera uma relação de confiança e afetividade entre o atendido e o profissional da psicologia, bem como uma corresponsabilização pela produção de saúde. Permite ainda a "circulação dos afetos", jă que marca a entrega, a disponibilidade e o afeto de ambos em um "laço", tendo como objetivo primaz do encontro o desenvolvimento da saúde do atendido.

O ponto de partida da construção vincular tem seu centro no interesse de ambos os lados, do psicólogo e do atendido. Esse interesse inclui a dedicação e o afeto que o profissional tem por sua atuação, o que decorrerá no espelhamento desse sentimento no sujeito, a dedicação, o cuidado e a compreensão que trará para o ambiente terapêutico e, por fim, a responsabilidade com outro sujeito, assim como tem por si (BARBOSA; BOSI, 2017). Com relação ao indivíduo que busca esse cuidado, tem como parte, também, a responsabilidade no processo, a vontade, a disponibilidade e a crença em resultados positivos. Concepção compartilhada por Rodrigues (2014), que faz uso do termo "aliança terapêutica", utilizado primariamente pela psicanalista Elizabeth Zetzel para nomear esse fenômeno vincular, tendo por concepção o atributo de grande valor aos processos egóicos do paciente e sua percentual participação nos resultados positivos, 
assim como a responsabilidade do psicólogo ser pautada na empatia e respeito, o que proporciona um terreno fértil para todas as movimentações "transformáticas".

Esse fenômeno demonstrou grandes frutos terapêuticos, como pôde ser evidenciado em um estudo realizado por Luborsky, entre os anos de 1976 e 1994, em que foi possível averiguar que a aliança terapêutica funciona como uma evidência de resultados preditivos no processo terapêutico, transpondo sua posição fenomenológica para uma posição de ferramenta de grande valor (RODRIGUES, 2014). Logo, tendo em vista a importância do vínculo, cabe aos profissionais da psicologia uma maior dedicação nessa construção; por isso, as discussões e o aperfeiçoamento teórico durante a graduação são constantes e independem da disciplina. 0 início e a manutenção dessa ferramenta, muitas vezes, são geradores de ansiedade nos formandos, quando, ao final do curso, veem-se frente a frente com sujeitos e suas subjetividades. Além disso, os desafios enfrentados pelos estagiários para a construção do vínculo ultrapassam as suas ansiedades no momento em que se deparam com os medos e receios dos indivíduos que estão em busca do atendimento e que, em muitos casos, não sabem como funciona, não vão por vontade própria ou não tem o sentimento de responsabilidade devido à isenção de investimento financeiro - quando se trata de atendimentos gratuitos. Deparar-se consigo mesmo não é uma tarefa fácil, as resistências são inúmeras e, por isso, o manejo terapêutico requer dedicação, zelo, paciência e muita empatia, o que, com um vínculo forte e seguro torna-se uma ação fluida e de parceria (BARBOSA; BOSI, 2017).

Durante a graduação, houve a orientação de realizar uma construção vincular centrada na escuta e no acolhimento, sem muitas intervenções, a fim de "presentificar" e conhecer o sujeito. Essa ação, na modalidade presencial, contempla uma fala solta e aberta em que queixas são abordadas, sentimentos e sofrimentos são apresentados e o manejo requer olhar nos olhos, expressar respeito e compreensão - muitas vezes na simples oferta de lenços de papel, um copo com água ou um abraço. Além disso, é possível o uso de técnicas de desenhos, colagens, baralhos terapêuticos ou expressões corporais que permitem uma maior facilidade na apresentação dos conteúdos subjetivos.

Pensando-se o processo formativo de forma longitudinal, são cerca de cinco anos aprendendo e reunindo técnicas e ferramentas possíveis para um desempenho de êxito, para formar um vínculo seguro e forte com os sujeitos de quem cuidaremos. Em questão de dias, no entanto, tudo o que foi aprendido instalou-se em uma caixinha de incertezas; com a mesma rapidez que a COVID-19 espalhou-se em escala planetária, as dúvidas, os questionamentos e os receios invadiram a formação em psicologia. "Um passo para o lado", contudo, possibilitou uma revisão e a construção de uma - nova - prática, já experimentada e recém-nascida, na modalidade on-line; entretanto, ainda sem muitas referências estruturais que tornassem possível, com firmeza, o alinhamento de uma intervenção.

Isso trouxe a necessidade de uma pausa geral; discussões foram travadas desde opiniões contrárias atêo estabelecimento de algum consenso possível, e a "permissão" do estágio on-line ser promulgada, enquanto perdurar a pandemia, por parte do Ministério da Educação (MEC), mas, sobretudo, por parte do Conselho Federal de Psicologia (CFP) e da Associação Brasileira de Ensino de Psicologia (ABEP) - posicionamento oficializado na elaboração e na divulgação do caderno nomeado como Práticas e Estágios Remotos em Psicologia no Contexto da Pandemia do COVID-19: 
Recomendações (CFP, 2020a). Tal documento, enfaticamente, salienta a diferença entre o Ensino Remoto Emergencial e o Ensino à distância, já que o último não condiz com a regulamentação atual do curso de graduação em Psicologia, pois o Ensino Remoto Emergencial tem a concepção de um projeto pedagógico e a certificação pelo Conselho Nacional de Educação (CNE), posto o estado pandêmico ora vivenciado e o isolamento social por este imposto, bem como a possibilidade de, pela via das Tecnologias de Informação e Comunicação (TICS), seguir mantendo a prestação de alguns serviços.

Com base nesse documento, uma Instituição de Ensino Superior (IES) da cidade de Salvador na Bahia iniciou a reorganização de seus estágios. Alguns programas foram retirados, outros inseridos e outros tantos refeitos, possibilitando que todos os discentes que estavam no último ano de sua graduação pudessem realizar as suas práticas a contento. Para tornar essa prática viável na modalidade remota - on-line -, foi ofertada capacitação estruturada, de modo a assegurar uma atuação ética e fiel às regulamentações, apresentando-se, inclusive, o documento elaborado pelo CFP com as recomendações - conforme já citado. Durante a capacitação, foi recomendada a leitura complementar de materiais a respeito da saúde mental durante a pandemia, além de um compilado desses mesmos materiais apresentados de forma expositiva em alguns dos encontros. Dentre eles, priorizaram-se os documentos oficiais de autoridades sanitárias nacionais e internacionais respeitadas, e pesquisas já divulgadas na época (BRASIL, 2020a; ROCHA; BRAMBILLA; BARROS, 2020).

Assim, fez-se necessário orientar os profissionais da psicologia para o desenvolvimento de ambientes adequados de atendimento - fechados, silenciosos e privados -, em que fosse possível uma condução terapêutica sem interrupções e com garantia de sigilo; ao uso de ferramentas como o Zoom Cloud Meetings, que garantissem a segurança dos dados advindos dos atendimentos, por meio de programas de antivírus, antispyware e criptografias dos dados - os quais continuam tendo a obrigatoriedade de serem registrados e guardados; e à busca por informações confiáveis a respeito do contexto pandêmico e de como psicoeducar os usuários do serviço que trouxessem questões acerca desta situação (BRASIL, 2020a).

Com relação à pessoa atendida, trabalhou-se também a importância de orientar sobre as ferramentas e plataformas que seriam utilizadas durante o atendimento, informar sobre a importância do uso de fone de ouvido e de um local também fechado e privativo, para a garantia de sigilo e confidencialidade, e a possibilidade de manter um copo com água e um lenço próximo durante a sessão. Adicionalmente, se necessário, era possível, também, manejar recursos de psicoeducação a respeito das reações físicas e emocionais mais comuns ocasionadas pelo contexto da pandemia (BRASIL, 2020a).

Assim, frente a esse cenário de desconhecimentos, mas descobrindo novas formas de aprender e fazer a psicologia, os primeiros contatos entre discentes e usuários do serviço iniciaram logo que findaram os encontros de capacitação. Destarte, o programa de estágio relatado nas presentes linhas, por ter parceria com um órgão público da área de Segurança Pública, demandou capacitações e orientações específicas para o atendimento a agentes de segurança pública, sendo necessária a construção de momentos qualificados de debate acerca das interfaces entre saúde e segurança. 


\subsection{Em tela, a Saúde Mental e a Segurança Pública}

O estágio evidenciado no presente relato adentrou os confins de um órgão público da área de Segurança Pública, demonstrando o olhar da psicologia para as questões implicadas nesse cenário. Para tal inserção, as discussões preparatórias foram alavancadas por produções científicas que apresentam um pouco da realidade vivenciada pelos agentes de segurança. Tais produções alertaram, logo a princípio, para um dado importante: as atividades laborais de algumas profissões têm se mostrado como facilitadoras no "desenvolvimento de patologias" e, devido a isso, o campo da Saúde do Trabalhador vem, cada vez mais, ganhando atenção. Segundo Castro, Rocha e Cruz (2019), estudos internacionais demonstram que pessoas abandonam seus empregos em decorrência de problemas de saúde mental. Ao analisar a relação entre trabalho e saúde mental, por sua vez, Amador et al. (2002) julgam ser de fundamental importância considerar os policiais como trabalhadores que sofrem o impacto do trabalho sobre a sua subjetividade e saúde, como afirmam Nogueira e Moreira (1999):

Tais organizações apresentam particularidades que devem ser levadas em consideração, uma vez que apresentam regras de convivência e ideais que permeiam as relações de trabalho e as relações interpessoais, que têm influências no psiquismo de seus integrantes. Ao ingressarem na polícia militar, por exemplo, diz-nos o autor, os sujeitos são concitados a se destituírem de valores e crenças para incorporarem os valores preconizados pelos regulamentos da instituição. Inicialmente, sentem o impacto das regras na convivência social intramuros, onde as relações perdem a naturalidade e se revestem de medo, de receio do erro e de tudo que ele pode acarretar (AMADOR et al., 2002, p. 03, adaptado, grifo nosso).

Em paralelo, indicadores como estressores sociais e organizacionais contribuem ainda mais para o agravamento desse quadro de adoecimento mental. Os estressores sociais surgem com a expectativa da sociedade para com o profissional de segurança pública, em termos de que este apresente um comportamento modelo.

Pesquisas têm associado esses estressores ao absenteísmo, à insatisfação profissional, à exaustão emocional, à rotatividade no trabalho, às doenças físicas e mentais, constituindo-se (pelo acesso fácil à arma) em um dos grupos profissionais com maior índice de suicídios (CASTRO; ROCHA; CRUZ, 2019, p. 527, grifo nosso).

Já os estressores organizacionais se manifestam com rotinas extensas de trabalho, convivência diária com a violência, além da ausência de suporte dos líderes, em muitos casos. Dados como esses evidenciam a importância de pôr em prática as políticas públicas desenvolvidas para trabalhadores, visando ao acolhimento, bem como a uma maior assistência quanto à saúde mental desses profissionais. A realidade, porém, é diferente, pois, segundo Perez, Bettega e Merlo (2017, p. 02), na interface entre saúde e segurança pública, "historicamente, as políticas nacionais de saúde mostraram-se ineficazes e ineficientes para enfrentarem as reais necessidades da população".

Desse ponto, o primeiro passo, dentro de qualquer prestação de serviços em psicologia, é o reconhecimento da área em que atuaremos, com o objetivo de obter informações sobre o 
contexto e os indivíduos nela inseridos, sendo então necessário levantamento e estudo de textos que abordem a realidade vivida por esses profissionais. Seguindo essa estratégia, foram analisados textos abordando a saúde mental de trabalhadores, o processo de trabalho, a relação da psicologia com a segurança pública, entre outros temas que possibilitaram, em supervisão, uma tentativa de aproximação desse contexto, bem como o reconhecimento das problemáticas enfrentadas por profissionais da segurança pública.

Assim, ao nos depararmos com o público em questão, foi possível perceber outras questões que acompanham o peso de suas atividades laborais, fazendo-se necessário reconhecer o quanto a cultura organizacional interfere no comportamento de seus funcionários; já que, de acordo com os autores já mencionados Castro, Rocha e Cruz (2019), a organização do trabalho é salientada como fonte de produção de identidade, mas também de adoecimento, sendo a carga de trabalho um fator de risco importante para agravos à saúde mental. Nesse sentido, os primeiros contatos com as pessoas por nós atendidas evidenciam estes dados:

A jornada de trabalho extenuante e irregular (...) e, muitas vezes, demanda do profissional a necessidade de complementação da renda por meio de trabalho externo irregular, expondo-se a riscos adicionais (...). Talvez isso explique o resultado de sofrerem duas vezes mais violência do que os policiais de nível superior. Além disso, a convivência familiar restrita é uma variável importante para o menor suporte social (CASTRO; ROCHA; CRUZ, 2019, p. 532-533).

Ainda sobre a cultura organizacional, os aspectos relevantes como a restrição da confiança entre líderes e liderados, bem como os mecanismos disciplinares fazem parte da rotina desses trabalhadores, contribuindo, por exemplo, para a construção de estigmas em torno do atendimento psicológico, estabelecendo-se como um rótulo para aqueles profissionais que consultam esse tipo de serviço. Dizem-nos Castro, Rocha e Cruz (2019) que a cultura organizacional hierárquica das polícias, que impõe mecanismos disciplinares de vigilância e controle, amplifica as barreiras entre os grupos profissionais dentro da instituição e restringe a confiança e a cooperação mútua, aspectos fundamentais às estratégias de enfrentamento no trabalho policial, especialmente quando em operação de campo.

Veem-se ecos disso no processo de procura por auxílio psicológico por parte desses agentes, visto que, do público atendido por nós na experiência deste estágio, apenas $20 \%$ do contingente constituía-se pelos agentes - segundo levantamento documental realizado -, sendo, então, a maior procura por parte dos seus familiares. Acerca disso, Barbosa e Menezes (2017, p. 14), em pesquisa, destacam que: "os policiais entrevistados sentem falta de apoio para si e para sua família, porque relatam que o trabalho influencia bastante suas relações familiares, tanto positivamente quanto negativamente". Em outras palavras, ainda que esses agentes não procurem, de forma direta, a oferta de serviços psicológicos, a procura por parte de seus familiares demanda atenção.

Considerando o contexto de pandemia em que estamos inseridos e a necessidade do uso das Tecnologias da Informação e Comunicação (TICs) para o atendimento on-line, deparamo-nos ainda com um novo desafio: o da vinculação. Ainda não existem dados que evidenciem sobre vinculação terapêutica para com agentes da segurança pública, em especial considerando contextos pandêmicos ou remotos. Chama-nos a atenção a necessidade de ponderar se o ambiente virtual poderia ser um facilitador ou um dificultador desses laços vinculares. 
Da prática, vale também o registro de que, como medida de atuação qualitativa, foi necessário instrumentalizar os pacientes para que houvesse domínio das ferramentas digitais, eliminando qualquer possibilidade de desconforto devido a isso; para tanto, entrou-se em contato antes da sessão com um tutorial referente à instalação e uso dessas tecnologias. No dia do encontro, para verificar qualquer dificuldade da parte do paciente, foi questionado como foi o acesso e reforçado acerca das ferramentas disponíveis, aumentando assim a familiaridade com a plataforma e ofertando soluções viáveis em caso de problemas.

Dentro desse processo, documentos utilizados no atendimento presencial passaram à versão digital, fazendo-se necessário preencher a ficha de inscrição com dados sociodemográficos do paciente, bem como sua frequência nos atendimentos; em seguida, a ficha de triagem contendo as informações recolhidas no primeiro encontro, e a ficha de evolução com o progresso realizado, além do termo de consentimento, lido junto com o paciente e assinado digitalmente. $O$ contrato terapêutico, comum a qualquer atendimento, precisou ser ajustado às novas demandas desse ambiente virtual, assim como a sinalização da impossibilidade do acesso devido à conexão da internet ou até mesmo a ciência de que o sigilo de um atendimento presencial ou on-line são os mesmos. Apesar de toda a preparação, a capacitação, o estudo e os cuidados implicados, alguns obstáculos na vinculação de alguns pacientes foram percebidos, pontos sobre os quais nos debruçaremos a seguir.

\subsection{Em tela, o Campo, as Estratégias Operacionais e os Desafios da Experiência}

Na prática de estágio, através do atendimento on-line de profissionais de segurança pública e seus familiares, houve diferentes nuances no contato e na construção de vínculo com os pacientes. Foi percebido que a baixa adesão dos agentes de segurança pública estava relacionada à resistência desse público em realizar atendimentos virtuais. Inicialmente foi requisitado que os atendimentos fossem realizados por celulares específicos, o que acabou não sendo viável por conta da quantidade de estagiários e da dificuldade de alinhar junto às lideranças de segurança pública como seria a aquisição desses aparelhos.

Ao se trabalhar com tais sujeitos, é fundamental levar em conta o contexto em que se insere o sigilo dos atendimentos, já que foi percebido que poderia haver o receio de que a conversa estivesse sendo gravada ou que pudesse ser relatada aos seus superiores. Sendo assim, destacase a importância de estabelecer um vínculo baseado no sigilo dos atendimentos, ao ser falado sobre a criptografia das plataformas virtuais, assim como do que está garantido no Código de Ética Profissional do Psicólogo e seus princípios fundamentais. Como aponta o CFP (2020a), as práticas de estágio on-line precisam garantir esse sigilo, da mesma forma que os estudantes precisam conhecer as ferramentas utilizadas nesses processos remotos.

Existe, ainda, mais uma barreira para esses agentes participarem de atividades que desconheçam o outro; no caso, o estagiário, por exemplo, ao contar sobre sua história de vida a uma pessoa considerada estranha. Amador et al. (2002) apontam que os policiais encontram dificuldades quando se refere a relações interpessoais que não seguem os padrões e as regras de convivência da instituição militar. Dessa forma, é preciso compreender as particularidades presentes nessa instituição, bem como os códigos de conduta e regras que são estabelecidos, já 
que: "[...] inicialmente, sentem o impacto das regras na convivência social intramuros, onde as relações perdem a naturalidade e se revestem de medo, de receio do erro e de tudo que ele pode acarretar" (AMADOR et al., 2002, p. 3).

Outro ponto que vale destacar quanto a tais práticas, é o atendimento aos familiares dos agentes de segurança pública. A inserção dos familiares desses agentes como possíveis pacientes aumentaram as expectativas quanto às práticas a serem realizadas. Estava previsto, no programa de estágio, o atendimento on-line apenas de profissionais de segurança pública; contudo, diante da dificuldade em alcançar tal público e da necessidade que apresentaram alguns desses familiares, foi flexibilizada e aceita a entrada desses sujeitos. Sendo assim, os familiares foram atendidos de forma individual, em modelo similar à oferta dada aos agentes, na qual foram relatadas as mais diversas queixas, as quais não estavam, necessariamente, relacionadas ao trabalho exercido pelo familiar como agente de segurança pública.

Foi alinhado que cada estagiário faria o contato com os possíveis assistidos no serviçoescola de psicologia para a marcação da triagem. Esse primeiro momento de triagem dos pacientes passou a ser também a primeira oportunidade para escutar as queixas desses profissionais e familiares, assim como estabelecer o início do processo de vinculação e confiança. A marcação de data e horário dos atendimentos, de responsabilidade dos estagiários, foi realizada a partir das plataformas indicadas e, nesses contatos, houve algumas adversidades como: a falta de disponibilidade de dia ou horário dos sujeitos; a dificuldade em estabelecer um diálogo através de mensagens assíncronas; a pactuação de data e horário de atendimento dentro dos horários estabelecidos pelo serviço-escola da instituição; encontrar disponibilidade de sala e remarcação de datas por conta da grande quantidade de alunos de outros estágios e seus pacientes; entre outras questões.

Apesar das adversidades visualizadas, segundo Rodrigues (2014), é possível a construção da aliança terapêutica nos contextos de atendimento on-line. Apesar disso, como constatamos, a construção do vínculo por meio de uma plataforma virtual enfrentou algumas barreiras e limitações tecnológicas, como a conexão de internet do sujeito assistido e o tempo limite dos atendimentos. É preciso ressaltar que, para os atendimentos, era necessário conectar áudio e vídeo, o que exigia bastante da conexão de muitos pacientes, sendo necessário lançar mão da criatividade para manejar os atendimentos. Com relação ao tempo, as sessões tiveram duração de cinquenta minutos, sendo relatado por alguns, ainda, a necessidade de interrupção dos atendimentos, de forma que algumas sessões foram finalizadas com pendências para sessões seguintes.

Não obstante, apesar destas dificuldades, pontos altos são evidenciados: há uma autopercepção relatada por vários pacientes quanto aos benefícios da escuta e do acolhimento psicológico especialmente em um contexto pandêmico como o de agora vivenciado. Há uma constatação de que, em poucos encontros, o manejo vincular foi possível e os pacientes sentiamse mais à vontade para narrar suas histórias, permitindo aos estagiários um desenvolvimento interessante do papel de psicólogo.

Logo, a partir desses pontos levantados, cremos ter sido possível perceber a importância de se estar preparado para um contato empático e de olhar humano para com o outro. Embasados teoricamente, lidamos com as adversidades enfrentadas nos atendimentos e fomos 
capazes de evidenciar práticas possíveis para a psicologia frente ao cenário remoto, evidenciando, assim, a capacidade não só da profissão em produção de adaptações, mas também da formação em psicologia, perfazendo uma prática profissional que, ao se deparar com obstáculos e com ineditismos, não perde suas bases teóricas e técnicas, mas é capaz de se adaptar para a boa consecução de seus serviços.

\section{CONSIDERAÇÕES FINAIS}

A formação em psicologia é uma transformação não só de conhecimento como também, e principalmente, uma maturação e crescimento dos próprios sujeitos que caminham por essas trilhas. Cuidar da saúde mental de outra pessoa tem por obrigação o posicionar de forma empática, respeitosa e acolhedora, despindo-se dos julgamentos, crenças pessoais e moralidades que impeçam de olhar o sujeito exposto como humano diante de outro ser humano. A vinculação, assim, encontra terreno fértil para prosperar e frutificar em ganhos terapêuticos.

As vivencias e experiências em cada disciplina do curso de psicologia proporcionam uma construção teórica suficiente e necessária para a atuação dos estagiários do presente relato de experiência. Os anseios e receios foram, muitas vezes, apaziguados pelos relatos da atuação dos docentes, bem como pela possibilidade de produção de capacitações, que municiaram os estagiários com as informações básicas para o planejamento de uma intervenção adequada.

Em processo de finalização de sua graduação, os formandos foram diretamente impactados pela pandemia. A COVID-19 colocou em xeque os conhecimentos profissionais, demandando das instituições de regulação a reinvenção de seus próprios funcionamentos. Com o aval dos órgãos responsáveis pela liberação dos estágios remotos, outrossim, os estudantes depararam-se com dúvidas que não conseguiam ser apaziguadas pelas respostas padronizadas de nossa profissão - também aprendiz nesse período pandêmico. Mesmo com toda a cautela, o cuidado e o respeito às instituições, a ansiedade e o medo tomaram uma nova forma e proporção; e o imaginário dos formandos encontrou um vácuo na teoria aprendida nos anos acadêmicos.

A capacitação proposta pela instituição de Ensino Superior acalentou os estudantes e possibilitou um leve vislumbre da atuação, mas ainda cercada por preconceitos e incertezas. A lista de ferramentas a serem usadas e os comportamentos a serem desempenhados antes e durante os atendimentos não estavam claros e cada possibilidade de fala, de instrumento, de organização do ambiente e da própria vestimenta eram sempre averiguados com os docentes e supervisores dos estágios, o que, mesmo com o aval e possíveis correções, não eram suficientes para sanar as incertezas e inseguranças - reforçando a nossa sugestão quanto à relevância de tais capacitações em experiências vindouras.

A parceria com o órgão público da área de Segurança Pública em questão, por sua vez, foi bastante gratificante e esperada pelos presentes estagiários; contudo, a demora para a liberação e reorganização dos atendimentos, encurralaram os formandos em seus medos e frustrações quanto à formação qualificada e à atuação com esses profissionais. As discussões e produções teóricas a respeito da saúde mental dos agentes de segurança pública, proposta pelos supervisores, contribuíram para a construção de possíveis atuações e para o conhecimento sobre 
essa comunidade, a despeito de tais dificuldades. Uma pequena luz em meio à turvação da atuação profissional que se avizinha.

Ainda sobre as discussões e produções teóricas realizadas, foi possível uma aproximação com a realidade vivida pelos profissionais de segurança pública, trazendo um tom de familiaridade para as possíveis intervenções futuras. No que tange o atendimento remoto, foi necessário alinhar as expectativas entre o mundo ideal - o qual supostamente seria o atendimento presencial - e o real - tratando-se então do atendimento virtual, visto que estamos atravessando uma pandemia com consequências inimagináveis. Em toda a graduação, esperouse por esse momento que precisou ser reinventado na direção de uma prática que respeitasse as indicações da Organização Mundial de Saúde (OMS) e atendesse às necessidades dos assistidos.

Assim como nossa prática, o público também foi se ajustando a essas expectativas anteriormente criadas, visto que a maior parte tratava-se dos familiares dos profissionais de segurança pública. Em seguida, a vinculação tornou-se o foco principal já que, em terrenos virtuais, a conexão da internet é o que define se haverá atendimento ou não, podendo transformar-se em justificativa para a não ocorrência do cuidado ou em ponte para o estabelecimento de laços e espaços de cuidado genuíno e interessado.

O terreno era novo; a missão, porém, era a de sempre: produzir qualidade de vida através de uma atenção em saúde mental qualificada. A partir do vivenciado, ficou evidente a presença do estigma quanto ao atendimento psicológico entre profissionais da segurança pública, por motivos já citados anteriormente, denotando a necessidade de conscientização com base nesse fator, pois a baixa procura por parte desses trabalhadores não anula a necessidade de atenção para a saúde mental - e pode, também, denotar dificuldades com o ambiente virtual.

Logo, a vinculação tende a se mostrar sempre como um desafio a ser encarado pelo psicólogo, independente do contexto virtual ou presencial. É necessário, porém, manter uma atenção maior em ambiente remoto, para que o paciente se sinta confortável e familiarizado com a ferramenta utilizada, bem como saiba que o sigilo e a confidencialidade são garantidos em qualquer contexto; e, para isso, colocar-se à disposição para quaisquer elucidações dessa natureza é fundamental.

Durante o contato com os assistidos, foi experienciado pelos formandos sentimentos como angústia e medo. Especialmente no estabelecimento dos contatos assíncronos em que as mensagens, muitas vezes, não eram respondidas pelos pacientes, gerando o medo quanto à continuidade dos atendimentos. Em alguns momentos, as sessões foram desmarcadas minutos antes do seu início, ou até mesmo durante o período do horário acordado. Experienciar tais momentos e sentimentos não foram fáceis, mas possibilitaram o amadurecimento quanto à prática psicológica e ao bom estabelecimento de contratos de trabalho, visando a um futuro como profissionais da psicologia, engajados de forma ética e social.

Neste momento, torna-se imprescindível, por fim, defender que na prática psicológica é preciso atuar alinhado a políticas públicas, a fim de desenvolver programas de assistência preventiva para profissionais que, porventura, estejam enfrentando alguma situação de ordem psicológica ou psicossomática; bem como, expandir o cuidado com a saúde mental que, não só para profissionais de segurança pública, mas para a população em geral, ainda apresenta-se como um estigma social. Da mesma maneira, é fundamental a criação de programas de 
conscientização para casos de uso de substâncias psicoativas, e uma transferência da atenção individual para a grupal, aumentando a rede de apoio e suporte social. Dessa forma, podem-se trilhar novos caminhos na atuação da psicologia junto à segurança pública.

\section{REFERÊNCIAS}

AMADOR, F. S. et al. Por um programa preventivo em saúde mental do trabalhador na Brigada Militar. Psicologia: Ciencia e Profissão, Brasília, DF, v. 22, n. 03, p. 54-61, 2002. Disponível em: http://doi.org/10.1590/S1414-98932002000300009. Acesso em: 26 Dez. 2020.

ASSI, G.; THIEME, A. L. Desafios na Psicoterapia Online: reflexões a partir de um relato de caso de uma paciente com ansiedade. Perspectivas em Análise do Comportamento, Santa Catarina, v. 10, n. 02, p. 267-279, 2020. Disponível em:

http://revistaperspectivas.emnuvens.com.br/perspectivas/article/view/629. Acesso em: 04 Jan. 2021.

BARBOSA, L. M.; MENEZES, C. N. B. A importância do apoio psicológico na saúde mental dos policiais militares de Fortaleza. Psicologia Argumento, Curitiba, v. 35, n. 89, p. 01-21, 2017. Disponível em: http://periodicos.pucpr.br/index.php/psicologiaargumento/article/view/25564. Acesso em: 04 Jan. 2021.

BARBOSA, M. I. S.; BOSI, M. L. M. Vínculo: um conceito problemático no campo da Saúde Coletiva. Physis: Revista de Saúde Coletiva, Rio de Janeiro, v. 27, n. 04, p. 1003-1022, out./dez. 2017. Disponível em: http://doi.org/10.1590/S0103-73312017000400008. Acesso em: 15 Dez. 2020.

BRASIL. Ministério da Saúde. Conselho Nacional de Saúde. Resolução n 196, de 10 de Outubro de 1996. Diário Oficial [da] República Federativa do Brasil: sessão 1, Brasília, v. 134, n. 201, p.21.082-21.085, out. 1996. Disponível em: https://bvsms.saude.gov.br/bvs/saudelegis/cns/1996/res0196_10_10_1996.html. Acesso em: 15 Jun. 2021.

BRASIL. Ministério da Saúde. Fundação Oswaldo Cruz. Saúde Mental e Atenção Psicossocial na Pandemia COVID - 19: Recomendações aos Psicólogos para o Atendimento Online. Brasília: MS/FIOCRUZ, 2020a. Disponível em: http://renastonline.ensp.fiocruz.br/recursos/saude-mental-atencao-psicossocialpandemia-covid-19-recomendacoes-aos-psicologos. Acesso em: 23 Dez. 2020

BRASIL. Ministério da Educação. Portaria $n^{\circ} 544$, de 16 de Junho de 2020. Dispõe sobre a substituição das aulas presenciais por aulas em meios digitais, enquanto durar a situação de pandemia do novo coronavírus - Covid-19, e revoga as Portarias MEC $n^{\circ} 343$, de 17 de março de 2020, $n^{\circ} 345$, de 19 de março de 2020, e n 473 , de 12 de maio de 2020. Diário Oficial da União: sessão 1, Brasília, DF, n. 114, p. 62, 17 jun. 2020b. Disponível em: http://www.in.gov.br/en/web/dou/-/portaria-n-544-de-16-de-junho-de-2020261924872. Acesso em: 02 Jan. 2021.

CASTRO, M. C.A.; ROCHA, R.; CRUZ, R. M. Saúde Mental do Policial Brasileiro: tendências teóricometodológicas. Psicologia, Saúde \& Doenças, Lisboa, v. 20, n. 02, p. 525-541, 2019. Disponível em: http://dx.doi.org/10.15309/19psd200220. Acesso em: 09 Jan. 2021.

CONSELHO FEDERAL DE PSICOLOGIA (CFP). Práticas e Estágios Remotos em Psicologia no Contexto da Pandemia da COVID-19: recomendações. Brasília, DF: CFP/ABEPSI, 2020a. Disponível em: http://site.cfp.org.br/publicacao/praticas-e-estagios-remotos-em-psicologia-no-contexto-da-pandemiada-covid-19-recomendacoes/. Acesso em: 15 Dez. 2020. 
CONSELHO FEDERAL DE PSICOLOGIA (CFP). Resolução CFP N. ${ }^{\circ}$ 02/1995. Dispõe sobre prestação de serviços psicológicos por telefone. Brasília: CFP, 1995. Disponível em: http://site.cfp.org.br/wpcontent/uploads/1995/02/resolucao1995_2.pdf. Acesso em: 09 Jan. 2021.

CONSELHO FEDERAL DE PSICOLOGIA (CFP). Resolução CFP N. ${ }^{\circ}$ 03/2000. Institui a Comissão Nacional de Credenciamento e Fiscalização dos Serviços de Psicologia pela Internet. Brasília: CFP, 2000. Disponível em: http://site.cfp.org.br/wp-content/uploads/2000/12/resolucao2000_6.pdf. Acesso em: 09 Jan. 2021.

CONSELHO FEDERAL DE PSICOLOGIA (CFP). Resolução CFP N. ${ }^{\circ}$ 04/2020. Dispõe sobre regulamentação de serviços psicológicos prestados por meio de Tecnologia da Informação e da Comunicação durante a pandemia do COVID-19. Diário Oficial da União: sessão 1, Brasília, DF, n. 61, p. 251, 2020b. Disponível em: http://www.in.gov.br/en/web/dou/-/resolucao-n-4-de-26-de-marco-de-2020-250189333. Acesso em: 09 Jan. 2021.

CONSELHO FEDERAL DE PSICOLOGIA (CFP). Resolução CFP N..$^{\circ}$ 11/2012. Regulamenta os serviços psicológicos realizados por meios tecnológicos de comunicação a distância, o atendimento psicoterapêutico em caráter experimental e revoga a Resolução CFP N. ${ }^{\circ}$ 12/2005. Diário Oficial da União: sessão 1, Brasília, DF, 25 jun. 2012. Disponível em: http://site.cfp.org.br/wpcontent/uploads/2012/07/Resoluxo_CFP_nx_011-12.pdf. Acesso em: 09 Jan. 2021.

CONSELHO FEDERAL DE PSICOLOGIA (CFP). Resolução CFP N. ${ }^{\circ} 11 / 2018$. Regulamenta a prestação de serviços psicológicos realizados por meios de tecnologias da informação e da comunicação e revoga a Resolução CFP n ${ }^{\circ}$ 11/2012. Diário Oficial da União: sessão 1, Brasília, DF, 14 mai., 2018. Disponível em: http://atosoficiais.com.br/cfp/resolucao-do-exercicio-profissional-n-11-2018-regulamenta-a-prestacaode-servicos-psicologicos-realizados-por-meios-de-tecnologias-da-informacao-e-da-comunicacao-erevoga-a-resolucao-cfp-n-112012. Acesso em: 09 Jan. 2021.

CONSELHO FEDERAL DE PSICOLOGIA (CFP). Resolução CFP N.$^{\circ}$ 12/2005. Regulamenta o atendimento psicoterapêutico e outros serviços psicológicos mediados por computador e revoga a Resolução CFP $N^{\circ}$ 003/2000. Brasília: CFP, 2005. Disponível em: http://cadastrosite.cfp.org.br/docs/resolucao2005_12.pdf. Acesso em: 09 Jan. 2021.

DALTRO, M. R.; FARIA, A. A. Relato de Experiência: Uma narrativa científica na pós-modernidade. Estudos e Pesquisas em Psicologia, Rio de Janeiro, v. 19, n. 01, p. 223-237, jan./abr. 2019. Disponível em: http://pepsic.bvsalud.org/pdf/epp/v19n1/v19n1a13.pdf. Acesso em: 07 Dez. 2020.

FARIA, G. M. Constituição do vínculo terapêutico em psicoterapia online: perspectivas gestálticas. Revista do NUFEN, Belém, v. 11, n. 03, p. 66-92, set./dez. 2019. Disponível em: http://pepsic.bvsalud.org/scielo.php?script=sci_arttext\&pid=S217525912019000300006\&lng=pt\&nrm=iso. Acesso em: 05 Jan. 2021.

MINAYO, M. C. S.; ASSIS, S. G.; OLIVEIRA, R. V. C. Impacto das atividades profissionais na saúde física e mental dos policiais civis e militares do Rio de Janeiro (RJ, Brasil). Ciência \& Saúde Coletiva, Rio de Janeiro, v. 16, n. 04, p. 2199-2209, 2011. Disponível em:

http://www.scielosp.org/article/csc/2011.v16n4/2199-2209/pt/. Acesso em: 15 Set. 2020.

NOGUEIRA, G. E. G.; MOREIRA, A. L. C. As formações grupais e seus efeitos nas instituições policiais militares. Revista de Psicologia: Saúde Mental e Segurança Pública, Belo Horizonte, n. 01, p. 35-39, jan./dez. 1999. Disponível em:

https://revista.policiamilitar.mg.gov.br/index.php/psicologia/article/view/79/189. Acesso em: 15 Jun. 2021.

OLIVEIRA, K. L.; SANTOS, L. M. Percepção da saúde mental em policiais militares da força tática e de rua. Sociologias, Porto Alegre, v. 12, n. 25, p. 224-250, dez. 2010. Disponível em: 
https://www.scielo.br/j/soc/a/kRWWYHPFpWbvhGmMdbjtqcp/abstract/?lang=pt. Acesso em: 12 Dez. 2020.

PEREZ, K. V.; BOTTEGA, C. G.; MERLO, A. R. C. Análise das políticas de saúde do trabalhador e saúde mental: uma proposta de articulação. Saúde em Debate, Rio de Janeiro, v. 41, n. spe2, p. 287-298, jun. 2017. Disponível em: http://doi.org/10.1590/0103-11042017s224. Acesso em: 09 Jan. 2021.

PIETA, M. A. M.; GOMES, W. B. Psicoterapia pela Internet: viável ou inviável?. Psicologia: Ciencia e Profissão, Brasília, v. 34, n. 01, p. 18-31, mar. 2014. Disponível em: http://doi.org/10.1590/S141498932014000100003. Acesso em: 07 Dez. 2020.

PIETA, M. A. M. et al. Desenvolvimento de protocolos para acompanhamento de psicoterapia pela Internet. Contextos Clínicos, v. 08, n. 02, p. 128-140, jul./dez. 2015. Disponível em: http://revistas.unisinos.br/index.php/contextosclinicos/article/view/ctc.2015.82.02. Acesso em: 09 Jan. 2021.

PINTO, E. R. As Modalidades do Atendimento Psicológico Online. Temas em Psicologia, Ribeirão Preto, v. 10, n. 02, p. 168-177, ago. 2002. Disponível em:

http://pepsic.bvsalud.org/scielo.php?script=sci_arttext\&pid=S1413-389X2002000200007\&lng=pt\&tlng=pt. Acesso em: 09 Jan. 2021.

ROCHA, R. V. S; BRAMBILLA, B. B.; BARROS, B. D. Saúde Mental em Contextos de Pandemia e Isolamento Social: Tarefas para as Trabalhadoras e Trabalhadores da Saúde. Revista Interfaces: Saúde, Humanas e Tecnologia, Juazeiro do Norte, v. 08, n. 03, p. 657-666, 2020. Disponível em: http://dx.doi.org/10.16891/2317-434X.v8.e3.a2020.pp657-666. Acesso em:20 Dez. 2020.

RODRIGUES, C. G. Aliança terapêutica na psicoterapia breve online. 2014. 96 f. Dissertação (Mestrado em Psicologia Clínica e Cultura) - Universidade de Brasília (UnB), Brasília, 2014. Disponível em: http://repositorio.unb.br/handle/10482/16596. Acesso em: 28 Dez. 2020.

SIEGMUND, G.; et al. Aspectos Éticos das Intervenções Psicológicas Online no Brasil: Situação Atual e Desafios. Psicologia em Estududo, Maringá, v. 20, n. 03, p. 437-447, set. 2015. Disponível em: http://www.periodicos.uem.br/ojs/index.php/PsicolEstud/article/view/28478. Acesso em: 09 Jan. 2021.

SIEGMUND, G.; LISBOA, C. Orientação Psicológica Online: Percepção dos Profissionais sobre a Relação com os Clientes. Psicologia: Ciência e Profissão, Brasília, v. 35, n. 01, p. 168-181, jan./mar. 2015. Disponível em: http://doi.org/10.1590/1982-3703001312012. Acesso em: 09 Jan. 2021.

SIEGMUND, G.; NONOHAY, R. G.; GAUER, G. Ensaio de usabilidade de uma intervenção psicoeducacional computadorizada sobre transtorno obsessivo-compulsivo. Temas em Psicologia, Ribeirão Preto, v. 24, n. 01, p. 261-276, 2016. Disponível em: http://dx.doi.org/10.9788/TP2016.1-18. Acesso em: 09 Jan. 2021.

SOUZA, E. R.; MINAYO, M. C. S. Policial, risco como profissão: morbimortalidade vinculada ao trabalho. Ciência \& Saúde Coletiva, Rio de Janeiro, v. 10, n. 04, p. 917-928, 2005. Disponível em: http://www.scielosp.org/article/csc/2005.v10n4/917-928/es/. Acesso em:26 Dez. 2020.

TEIXEIRA, C. F. S. et al. A saúde dos profissionais de saúde no enfrentamento da pandemia de Covid-19. Ciência e Saúde Coletiva, Rio de Janeiro, v. 25, n. 09, p. 3465-3474, set. 2020. Disponível em: http://dx.doi.org/10.1590/1413-81232020259.19562020. Acesso em: 02 Dez. 2020. 